\title{
Possible difference in the structure of acetylcholinesterase between insecticide susceptible and resistant strains of Culex tritaeniorhynchus resulted from structure-activity relationship of 3-alkylsulfonylphenyl methanesulfonates
}

\author{
Akira Mamiya, Yukio Ishikawa, Akio Masui ${ }^{1}$ and Yoshiaki Kono ${ }^{2, *}$ \\ Laboratory of Applied Entomology, Faculty of Agriculture, The University of Tokyo, Bunkyo-ku, Tokyo 113-0034, \\ Japan \\ ${ }^{1}$ Ageo Research Laboratory, Agro Chemicals Division, Fine Chemicals Group, Nippon Kayaku Co., Ltd., Ageo, Saitama \\ 362-0064, Japan \\ ${ }^{2}$ Department of Medical Entomology, National Institute of Infectious Diseases, Shinjuku-ku, Tokyo 162-8640, Japan \\ (Received 14 November 1997; Accepted 6 February 1998)
}

\begin{abstract}
Acetylcholinesterase (AChE) inhibiting activity of eight 3-alkylsulfonylphenyl methanesulfonates was measured and its relationship with the structure of substituted alkyl moieties was analyzed in susceptible and resistant strains of Culex tritaeniorhynchus. The activity of the compounds was not so potent as that for the green rice leafhopper, Nephotettix cincticeps, previously reported. However, a parabolic relationship of the activity was detected with the distance between the $\mathrm{S}$ atom and the distal $\mathrm{C}$ atom of the alkyl moiety. The shape of the parabolic curve and the optimum distance were the same in susceptible and resistant strains, but the activity was about 100 times higher for AChE of the susceptible strain than for that of the resistant strain. No significant relationship was detected with the steric constant. An activity structure relationship was, however, detected with the steric constant in $N$. cincticeps, but not with the distance S-C, based on the previous results. Considering that the sulfone moiety of methanesulfonates conjugates with the esteratic subsite of the AChE active site to inhibit its activity, a structural change apparently occurred in the esteratic subsite of $\mathrm{AChE}$ in the resistant strain of $C$. tritaeniorhynchus, and was different from that of $N$. cincticeps.
\end{abstract}

Key words: Insecticide resistance, Culex tritaeniorhynchus, methanesulfonate, acetylcholinesterase insensitivity, structure activity relationship

\section{INTRODUCTION}

One of the main mechanisms of organophosphate and carbamate insecticide resistance is genetic modification of acetylcholinesterase (AChE) (Fournier and Mutero, 1994). The Toyama strain of Culex tritaeniorhynchus showed an extremely high level of resistance to organophosphates (Kamimura and Maruyama, 1983). The resistance is due to insensitivity of the AChE to the insecticides (Takahashi and Yasutomi, 1987; Watanabe et al., 1991).

In the previous paper, we reported the biochemical characteristics of AChE accompanying the insensitivity to the inhibitors in the Toyama strain (Mamiya et al., 1997). AChE in the Toyama strain showed higher substrate specificity. When the acetylthiocholine (ATCh) was used as a substrate, the hydrolytic activity of AChE of the Toyama strain was one third that of the susceptible strain, Taiwan strain. Since the structural difference between acetylcholine (ACh) and ATCh lies in the length of the molecule binding to the esteratic subsite of the active site, we suggested that a substantial structural modification has occurred at the esteratic subsite.

In the present paper, we tested the inhibiting activity of the 3-alkylsulfonylphenyl methanesulfonates for AChE of the Toyama and Taiwan strains, to clarify the structural changes in the insecticide-insensitive AChE in more detail. Structure-activity relationship of 3-alkylsulfonylphenyl methanesulfonates has previously been studied for insecticide resistant and susceptible strains of the green rice leafhopper,

${ }^{*}$ To whom all correspondence should be addressed. 
Nephotettix cincticeps (Kato et al., 1988, 1989, 1990). The present study indicates that modification of AChE in the Toyama strain differs from that which occurred in $N$. cincticeps.

\section{MATERIALS AND METHODS}

Mosquitoes. The Toyama strain (Toyama) of C. tritaeniorhynchus, originating from a resistant field population in Toyama Prefecture (Takahashi and Yasutomi, 1987; Watanabe et al., 1991), was selected by fenitrothion (1 ppm) (Mamiya et al., 1997). The Taiwan strain, which was established in 1971 in Taipei, was used as a susceptible strain. The two strains were maintained in the laboratory under constant conditions of $25-27^{\circ} \mathrm{C}$, LD $16: 8$.

Preparation of enzyme source. One 3-4 day old adult was homogenized in $0.5 \mathrm{ml}$ of $50 \mathrm{~mm}$ Tris- $\mathrm{HCl}$ buffer solution ( $\mathrm{pH} 8.05$ ) containing $0.1 \%$ Triton $\mathrm{X}-100$ with a glass homogenizer on ice. The homogenate was centrifuged at $900 \times \mathrm{g}$ for $10 \mathrm{~min}$ at $4^{\circ} \mathrm{C}$ and then the supernatant was collected and used as an enzyme source. Mosquitoes were used regardless of sex.

Chemicals. Ten compounds of 3-alkylsulfonylphenyl alkanesulfonates (eight methanesulfonates NK-1-NK-8, one ethanesulfonate NK-9 and one propanesulfonate NK-10, see Table 1) were synthesized according to the methods of Kato et al. (1988). The chemicals used for the assay of AChE activity, dithiobisnitrobenzoic acid (DTNB) and ATCh iodide, were purchased from Wako Pure Chemical Industries Ltd. All other chemicals used in the experiments were of analytical grade.

Detection of AChE activity. The DTNB method by Ellman et al. (1961) was adopted with a minor modification to detect the AChE activity by microtitreplate assay. Forty microliters of enzyme source was added to each well containing $80 \mu \mathrm{l}$ of $50 \mathrm{~mm}$ Tris- $\mathrm{HCl}$ buffer solution ( $\mathrm{pH} \mathrm{8.05)}$ and $40 \mu \mathrm{l}$ of $0.9 \mathrm{M} \mathrm{NaCl}-0.36 \mathrm{M}$ $\mathrm{MgCl}_{2}$ solution. Then, $40 \mu \mathrm{l}$ of substrate solution ( $9 \mathrm{~mm}$ ATCh in distilled water) was added to each well and the plate was incubated at $30^{\circ} \mathrm{C}$ for $30 \mathrm{~min}$. After the incubation, $80 \mu \mathrm{l}$ of a $1: 1$ mixture of DTNB solution (10 mM DTNB$18 \mathrm{~mm} \mathrm{NaHCO}$ ) and eserine solution (4.8 mM) was added to each well to stop the reaction and stain the thiocholine produced by AChE activity. Optical density was measured at $412 \mathrm{~nm}$ on a Microplate Reader Model 450 (Bio-Rad). Activity of the enzyme was obtained by subtracting the value of the control (buffer solution was used in place of enzyme solution) from the observed value.

Inhibition of the AChE was measured by adding $40 \mu \mathrm{l}$ of various concentrations of the compounds to the reaction mixture $10 \mathrm{~min}$ before the incubation and observing residual activity after incubation. $I_{50}$ values for the AChE of Toyama and Taiwan were calculated by probit analysis using the SPSS program (SPSS Inc.).

Structural parameter. Three dimensional structures of methanesulfonates (NK-1 to NK-8) were estimated by a molecule modeling software, Biosym-Insight II (Biosym Technology Inc.). After the energy optimization calculation, the distance between the Sulfate atom (S) and the distal Carbon atom (C) of the alkylsulfonyl moiety was estimated. In case of branched alkyl moieties having two or three distal Cs, the longer distance was used for further analysis. Hancock steric constant (Hancock et al., 1961) was used as a steric parameter of the substituted moiety.

\section{RESULTS AND DISCUSSION}

Inhibitory activities $\left(-\log I_{50} \mathrm{M}\right)$ of the 3alkylsulfonylphenyl alkanesulfonates compounds tested are shown in Table 1 . In all the tested compounds, $-\log I_{50}$ values were less than 6 , even for the susceptible strain. The present results contrast with the previous ones obtained from AChE of $N$. cincticeps to which some compounds showed $-\log I_{50}$ value up to 8 (Kato et al., 1988). Inhibitory activity of the compounds was always about 100 times higher for the susceptible strain (Table 1). The inhibitory activities for susceptible AChE were highly correlated with those for insensitive AChE (Fig. 1, $Y=X-1.76, r=0.96$ ).

The relationship between the inhibitory activity of the compound (NK-2 to NK-8) for each strain and the distance between $\mathrm{S}$ and $\mathrm{C}$ is shown in Table 2 . When the inhibitory activity is plotted against the $\mathrm{S}-\mathrm{C}$ distance, parabolic curves can be fitted. The curves for the two 
Table 1. Inhibitory activity of NK compounds for AChEs in susceptible and resistant strains of $C$. tritaeniorhynchus and structural parameters of the compounds

\begin{tabular}{|c|c|c|c|c|c|c|}
\hline \multirow{3}{*}{ Compound } & & & \multicolumn{2}{|c|}{$\begin{array}{l}\text { Inhibitory activity } \\
\quad\left(-\log I_{50} \mathrm{M}\right)\end{array}$} & \multicolumn{2}{|c|}{ Structural parameter } \\
\hline & \multicolumn{2}{|c|}{$\mathrm{SO}_{2} \mathrm{R} 2$} & \multirow{2}{*}{ Susceptible } & \multirow{2}{*}{ Resistant } & \multirow{2}{*}{$\begin{array}{l}\text { Distance } \\
\text { (S-C) ( } \\
(\AA)\end{array}$} & \multirow{2}{*}{$\begin{array}{c}\text { Hancock } \\
\text { steric constant }\end{array}$} \\
\hline & $\mathrm{R} 1$ & $\mathrm{R} 2$ & & & & \\
\hline NK-1 & Methyl & Methyl & & & 1.79 & 0.00 \\
\hline NK-2 & Methyl & Ethyl & 3.01 & 1.00 & 2.83 & -0.38 \\
\hline NK-3 & Methyl & $n$-Propyl & 5.05 & 3.24 & 4.16 & -0.67 \\
\hline NK-4 & Methyl & iso-Propyl & 2.29 & 1.00 & 2.79 & -1.08 \\
\hline NK-5 & Methyl & $n$-Butyl & 4.82 & 3.11 & 5.32 & -0.70 \\
\hline NK-6 & Methyl & sec-Butyl & 4.31 & 2.36 & 3.25 & -1.74 \\
\hline NK-7 & Methyl & iso-Butyl & 5.35 & 3.77 & 4.17 & -1.24 \\
\hline NK-8 & Methyl & $n$-Pentyl & 4.06 & 2.30 & 5.82 & -0.71 \\
\hline NK-9 & Ethyl & n-Propyl & 4.48 & 2.39 & & \\
\hline NK-10 & $n$-Propyl & $n$-Propyl & n.d. ${ }^{\mathrm{c}}$ & n.d. ${ }^{c}$ & & \\
\hline
\end{tabular}

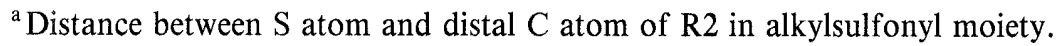

${ }^{\mathrm{b}}$ Hancock steric constant of R2.

${ }^{\mathrm{c}}$ Not determined.

AChEs has a similar shape and have a common peak (Fig. 2). The optimum S-C distance for inhibitory activity is 4.55 for both AChEs, and the activity declines greatly as the $\mathrm{S}-\mathrm{C}$ distance becomes longer or shorter than the optimum. When the activity was plotted against a Hancock steric constant, no curve could be fitted with statistical significance (Table 2).

A relationship between the structure of the

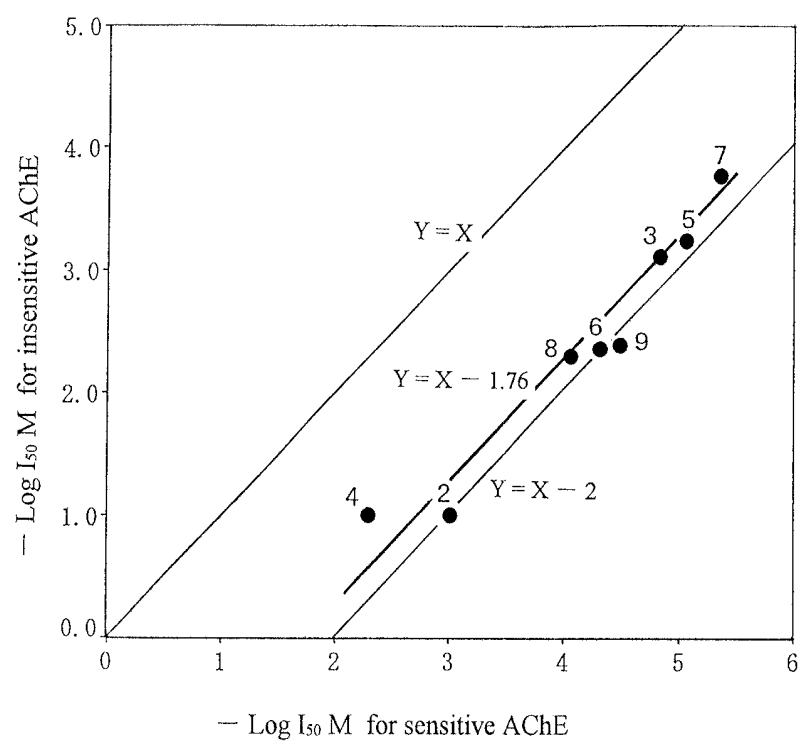

Fig. 1. Correlations of inhibitory activity of NK compounds against sensitive and insensitive AChEs in $C$. tritaeniorhynchus. The numbers correspond with the compounds in Table 1. compound and its inhibitory activity against AChE has previously been reported for N. cincticeps (Kato et al., 1990). The AChE inhibi-

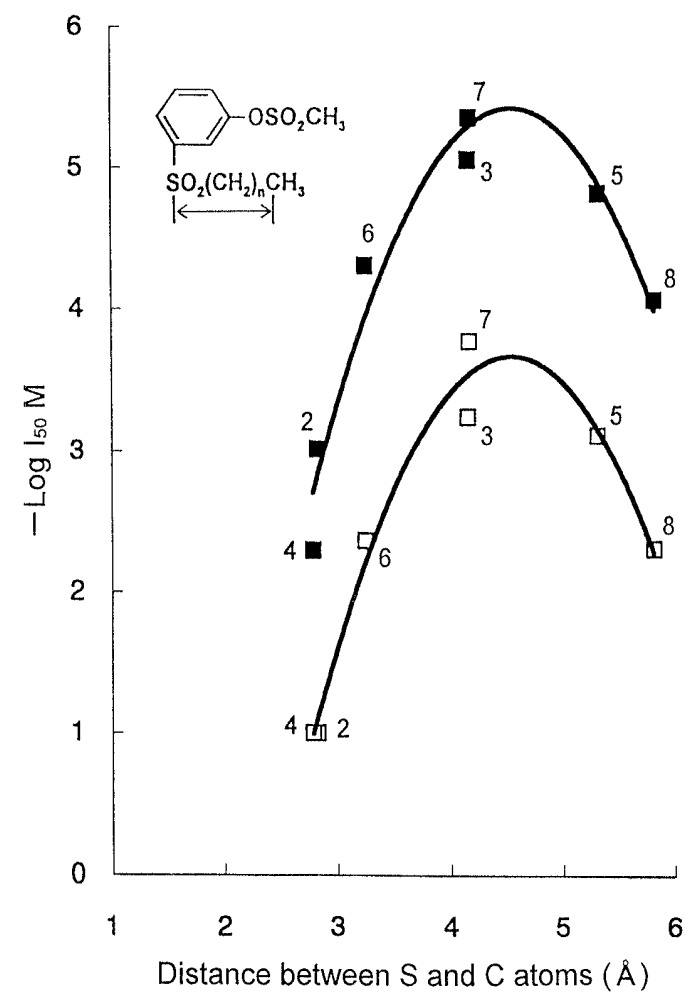

Fig. 2. Relationships between S-C distance and inhibitory activity of NK compounds for sensitive (solid square) and insensitive (open square) AChEs in C. tritaeniorhynchus. The numbers correspond with the compounds in Table 1. 
Table 2. Statistical analysis on the parabolic relationship between structural parameters and AChE inhibition activities of NK compounds

\begin{tabular}{lccl}
\hline $\begin{array}{c}\text { Species } \\
\text { (Compound) }\end{array}$ & Strain & \multicolumn{1}{c}{$\begin{array}{c}\text { Distance (S-C) } \\
(\AA)\end{array}$} & \multicolumn{1}{c}{$\begin{array}{c}\text { Steric constant } \\
(-)\end{array}$} \\
\hline $\begin{array}{l}\text { C. } \text { tritaeniorhynchus } \\
\text { (NK-1-NK-8) }\end{array}$ & Susceptible & $\begin{array}{c}r^{2}=0.945(p=0.003) \\
Y=-0.88(X-4.55)^{2}+5.41\end{array}$ & $r^{2}=0.159(p=0.708)$ \\
& & $\begin{array}{l}Y=0.975) \\
r^{2}=0.975(p=0.001)\end{array}$ & $r^{2}=0.046(p=0.991)$ \\
N. cincticeps & Resistant & $Y=-0.86(X-4.55)^{2}+3.66$ & \\
& Susceptible & $r^{2}=0.596(p=0.104)$ & $r^{2}=0.847(p=0.009)$ \\
& & & $Y=-1.30(X-1.26)^{2}+9.13$ \\
& Resistant & $r^{2}=0.704(p=0.048)$ & $r^{2}=0.952(p=0.001)$ \\
& & & $Y=-0.97(X-1.66)^{2}+8.85$ \\
\hline
\end{tabular}

$r^{2}$ : correlation index, $p$ : significance level.

tory activities of the compounds that were used in their study (6-alkylthio-2-pyridyl methanesulfonates) are comparable to those of the compounds used in the present study (Kato et al., 1988, 1990). Inhibitory activity of these compounds against the insecticide susceptible and resistant strains of $N$. cincticeps are shown in Table 3 . In the case of $N$. cincticeps, a statistically significant parabolic relationship was obtained between the steric constant and the inhibitory activity, but not for the other structural parameters (Fig. 3, Table 2). Inhibitory activity was maximized when the steric constant was -1.26 for the susceptible strain (S), and -1.66 for the resistant strain (R). These results suggest that the inhibitory activity ap- parently changes according to the bulkiness of the alkyl moiety, rather than the S-C distance in $N$. cincticeps.

When the data of 15 substituents were used for the analysis (Kato et al., 1990), the parabolic curve for the resistant strain $\left\{\mathrm{R}^{\prime}: Y=-1.53(X\right.$ $\left.-1.44)^{2}+8.97, r^{2}=0.87, p<0.001\right\}$ changed a little from that based on the data of 8 substituents $\left\{Y=-1.28(X-1.31)^{2}+9.08, r^{2}=0.78\right.$, $p<0.001\}$, and the differences in both optimum steric constant and maximum inhibitory activity between susceptible and resistant strains were reduced. It has been reported that methanesulfonic acid ester having quaternary ammonium inhibits AChE by acting on an esteratic subsite of the AChE (Ginsburg, 1962;

Table 3. Inhibitory activity of NK compounds for AChEs in susceptible and resistant strains of N. cincticeps and structural parameters of the compounds

\begin{tabular}{|c|c|c|c|c|c|}
\hline \multirow{2}{*}{ Compound } & \multirow{2}{*}{$\begin{array}{l}{ }_{\mathrm{R}}{ }_{\mathrm{SO}}-\mathrm{OSO}_{2} \mathrm{CH}_{3} \\
\end{array}$} & \multicolumn{2}{|c|}{$\begin{array}{l}\text { Inhibitory activity } \\
\quad\left(-\log I_{50} \mathrm{M}\right)\end{array}$} & \multicolumn{2}{|c|}{ Structural parameter } \\
\hline & & Susceptible & Resistant & $\begin{array}{l}\text { Distance }^{\mathrm{b}} \\
(\mathrm{S}-\mathrm{C})(\AA)\end{array}$ & $\begin{array}{c}\text { Hancock } \\
\text { steric constant }^{\mathrm{c}}\end{array}$ \\
\hline NK-1' & Methyl & 7.17 & 6.07 & 1.81 & 0.00 \\
\hline $\mathrm{NK}-2^{\prime}$ & Ethyl & 8.02 & 7.22 & 2.78 & -0.38 \\
\hline NK-3' & n-Propyl & 8.70 & 8.08 & 4.16 & -0.67 \\
\hline NK- $4^{\prime}$ & iso-Propyl & 9.52 & 8.30 & 2.78 & -1.08 \\
\hline NK- $5^{\prime}$ & $n$-Butyl & 8.80 & 8.22 & 5.31 & -0.70 \\
\hline NK- $6^{\prime}$ & sec-Butyl & 8.70 & 9.00 & 3.25 & -1.74 \\
\hline $\mathrm{NK}-7^{\prime}$ & iso-Butyl & 9.15 & 8.40 & 4.19 & -1.24 \\
\hline NK- $8^{\prime}$ & $n$-Pentyl & 8.15 & 8.00 & 5.82 & -0.71 \\
\hline
\end{tabular}

${ }^{a}$ Data on the previous paper, Kato et al., 1990.

${ }^{\mathrm{b}}$ Distance between $\mathrm{S}$ atom and distal $\mathrm{C}$ atom of $\mathrm{R}$ in alkylsulfonyl moiety.

${ }^{c}$ Hancock steric constant of $R$. 


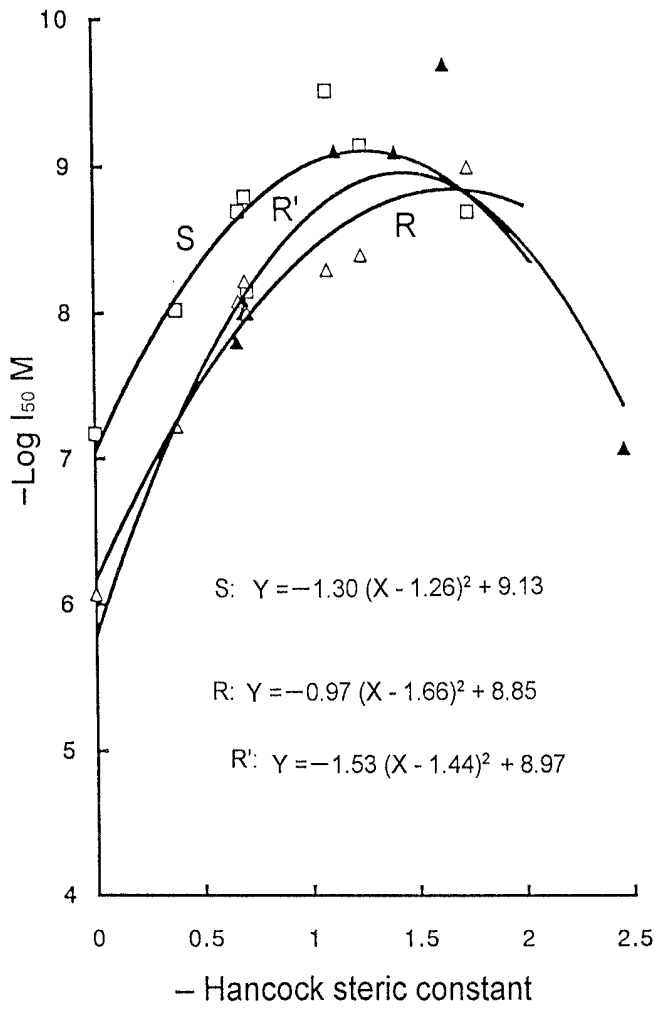

Fig. 3. Relationships between Hancock steric constant and inhibitory activity of NK compounds 6-alkylsulfonyl-2-pyridyl methanesulfonates for AChEs in susceptible ( $\mathrm{S}$, open square) and resistant ( $\mathrm{R}$, open triangle) strains of $N$. cincticeps. The numbers correspond with the compounds in Table 3. $\mathrm{R}^{\prime}$ (open and solid triangle) was calculated based on 15 substituents in the previous paper (Kato et al., 1990).

Kitz and Wilson, 1962). Considering the structure model of AChE (Sussman et al., 1991), alkylsulfone moiety substituted for quaternary ammonium in NK compounds appears to bind with the choline binding subsite of the AChE. The results for the susceptible and resistant $C$. tritaeniorhynchus showing no difference in shape and optimum S-C distance of the parabolic curve suggest that no structural modification has occurred in the choline binding subsite. We have already suggested a structural modification in the esteratic subsite of the $\mathrm{AChE}$ in resistant $C$. tritaeniorhynchus (Mamiya et al., 1997), based on the differences in the substrate specificity and the organophosphate sensitivity between the two AChEs. The present results are consistent with this proposal. In $N$. cincticeps, susceptible and resistant AChEs showed a similar fluctuation in sensitivity to alkylsulfonyl methanesulfonates suggest- ing that structural modification in the resistant AChE was different from that in $C$. tritaeniorhynchus. It is concluded that the structure of the active site of insecticide susceptible AChE and structural modification by insecticide resistant AChE varies among insect species. Analysis of $\mathrm{AChE}$ gene sequence in these insects is now in progress.

\section{ACKNOWLEDGEMENTS}

This work was supported in part by Grants-in-Aid (No. 07556013, No. 07660067) from the Ministry of Education, Science, Sports and Culture of Japan.

\section{REFERENCES}

Ellman, G. L., K. D. Coutny, U. Anders and K. M. Featherstone (1961) A new and rapid colorimetric determination of acetylcholinesterase activity. Biochem. Pharmacol. 7: 88-95.

Fournier, D. and A. Mutero (1994) Modification of acetylcholinesterase as a mechanism of resistance to insecticides. Comp. Biochem. Physiol. 108C: 19-31.

Ginsburg, S. (1962) Methanesulfonates of tertiary and quaternary amino alcohols. J. Med. Pharm. Chem. 5: 1364-1367.

Hancock, C. K., E. A. Meyer and B. J. Yager (1961) Quantitative separation of hyperconjugation effects from steric substituent constants. J. Am. Chem. Soc. 83: 4211-4213.

Kamimura, K. and Y. Maruyama (1983) Appearance of highly resistant strain of Culex tritaeniorhynchus to organophosphorus insecticides. Jpn. J. Sanit. Zool. 34: 33-37.

Kato, S., A. Masui and S. Ishida (1988) Chemical structures and insecticidal activity of 3-alkylthiophenyl alkanesulfonates. $J$. Pestic. Sci. 13: 107-115.

Kato, S., A. Masui and S. Ishida (1989) Chemical structures and insecticidal, acaricidal activities of 6-alkylthio-2-pyridyl alkanesulfonates. J. Pestic. Sci. 14: 11-22.

Kato, S., M. Kobayashi, A. Masui and S. Ishida (1990) Relationships between insecticidal activity of 6-alkylthio-2-pyridyl methanesulfonates and acetylcholinesterase inhibition of their sulfone derivatives against Nephotettix cincticeps. $J$. Pestic. Sci. 15: 63-69.

Kitz, R. and I. B. Wilson (1962) Esters of methanesulfonic acid as irreversible inhibitors of acetylcholinesterase. J. Biol. Chem. 237: 3245-3249.

Mamiya, A., Y. Ishikawa and Y. Kono (1997) Acetylcholinesterase in insecticide resistant Culex tritaeniorhynchus: Characteristics accompanying insensitivity to inhibitors. Appl. Entomol. Zool. 32: 35-42.

Sussman, J. L., M. Harel, F. Frolow, C. Oefner, A. Goldmand, L. Toker and I. Silman (1991) Atomic structure of acetylcholinesterase from Torpedo californica: A prototypic acetylcholine-binding protein. Science 253: 872-879.

Takahashi, M. and K. Yasutomi (1987) Insecticidal resistance of Culex tritaeniorhynchus in Japan: Genetics and mechanisms of resistance to organophosphorus insecticides. $J$. Med. Entomol. 24: 595-603.

Watanabe, M., Y. Takebe, R. Arakawa, K. Kamimura and K. Kobashi (1991) Susceptibility to nineteen insecticides and esterase activity in Anopheles omorii. Jpn. J. Sanit. Zool. 42: 33-42. 